\title{
INCREASING CAPACITY IN WORK WITH WAR VICTIMS AND MIGRANTS: PRAGMATIC EMPOWERMENT TRAINING (PET)
}

\author{
Charles David Tauber ${ }^{1}, \&$ Sandra Marić ${ }^{2}$ \\ ${ }^{1}$ M.D., CEO, Coalition for Work with Psychotrauma and Peace (Croatia and Netherlands) \\ ${ }^{2}$ MA, Deputy CEO, Coalition for Work with Psychotrauma and Peace (Croatia and Netherlands)
}

\begin{abstract}
According to a variety of publications and in our experience, there is a very large deficit in the number of people available to work with the psychological traumas of war and migration and other disasters, primarily those created by humans. While symptoms of such traumas may be relieved by drugs to some degree, drug treatment does not solve the basic issues. The consequences are a lack of functionality of the victims of trauma at various levels, as well as increased physical illness. Further, the training and employment of professionals is costly and time-consuming. In work by the first author since 1988 with asylum seekers and refugees in The Netherlands and since 1995 in the Western Balkans, we have found that "barefoot therapists", aka "peer supporters" from the beneficiary communities can be trained using participatory methods in about 150 hours to provide at very least first-line assistance using methods based on Carl Rogers' participatory education model. This also has the advantage of greater acceptance by the beneficiaries, especially in situations in which psychological treatment is stigmatized.
\end{abstract}

Keywords: Psychological trauma treatment, war trauma, peer support, asylum seekers, integration.

\section{Introduction}

There is a large amount of psychological traumatization among war victims and migrants as well as among members of minority groups in many parts of the world, not the least of them Europe and North America. In a series of articles in The Lancet in 2007, the standpoints of which were reiterated in October $2018^{1}$, it was said that more than $90 \%$ of the people needing psychological assistance weren't getting it. This, of course, is a much more severe situation in war-torn regions and among marginalized groups. The psychological issues cause a wide variety of additional consequences, such as a lack of functionality within families and societies, physical ailments, difficulty in integration into receiving societies, economic difficulties, and domestic and civil violence. It also is obvious that there are insufficient resources to train a sufficient number of psychologists and psychiatrists to deal with these numbers of people in adequate ways, particularly in environments where resources already are scarce. A further issue is that receiving psychological assistance is highly stigmatized in many cultures, especially in those groups most in need of assistance. Still another issue is the lack of understanding of the specific cultural, religious, and experiential factors by practitioners outside of the beneficiary groups.

The method now known as Pragmatic Empowerment Training (PET) has been developed through the experience of the first author in work with asylum seekers and refugees, first with various groups in The Netherlands starting in 1988, and later with the victims of war in the Western Balkans since 1995 as head of the Coalition for Work with Psychotrauma and Peace (CWWPP), and currently again with the victims of the migrant crisis in Europe and elsewhere. The aim of the method is to train people without previous education who are members of the beneficiary groups to assist one another in the first instance, referring to professionals only where absolutely necessary. The education and psychological supervision is given without charge online and onsite. The educational and therapeutic philosophy is that of Carl Rogers' participatory education.

\footnotetext{
${ }^{1}$ Lancet Global Mental Health Group, (2007). Scaling up services for mental disorders-a call for action. Lancet 2007; 370, $1241-52$.
} 


\section{The Issues}

\subsection{Recognition}

One of the primary issues is the lack of recognition by governments, inter-governmental agencies, large non-governmental organizations, and donors that psychological assistance and relief is essential for the recovery of people after war, torture, and other mistreatment. Frequently, it is seen by those in leadership as "soft" and often has been characterized as "irrelevant" in comparison to such factors as politics and economics. Psychological trauma has not been considered to be a primary factor in integration into society during and after conflict and in work with vulnerable groups, such as migrants.

Where such aid is given at all, it given for very short periods of time, frequently for only one or a very few sessions. Also, drugs rather than talk therapy almost always are used. The recent findings from research show us that level of use anti-depressives for 2017 is double in war-affected Vukovar-Sirmium County in comparison with the rest of the Croatia ${ }^{2}$. Further, Croatian police in 2007 reported that about a third of drivers in the region were using some sort of psychoactive drug. This applies even in situations that are somewhat more stable, such as recovery, integration, and development. Additionally, with very few exceptions, work on psychological trauma is not considered to be part of peacebuilding and reconciliation processes.

The problem of dealing with traumatic reactions is that, in most societies, it is overly medicalized. We strongly believe that it should be more socially and culturally sensitive. The term "psychosocial" attempts to express the recognition that there always is a close, ongoing circular interaction between an individual's psychological state and his or her social environment ${ }^{3}$. Such an approach is directly intertwined with peacebuilding work. In a broader concept of healing in which the individual is not treated as separate from his or her social context, the shift from "victim" to "survivor" is as much a question of social justice as a question of any personal process undertaken by the individual.

Summerfield argues that: "If symbolic acts are not linked with the delivery of truth, justice, and social change, they run the danger of being seen as a strategy to "buy off" the survivors. Social reform is the best medicine; for victims of war and atrocity this means public recognition and justice. Health and illness have social and political roots: post-traumatic reactions are not just a private problem, with the duty on the individual to recover, but an indictment of the socio-political forces that produced them."

A common definition of a traumatic situation is one that threatens the physical or psychological status of a person or entity or those of someone or something related in some way to the person or entity. Thus, a simple example would be an auto accident or a near miss to a person or to someone close. It might even be something similar with the same type of car or in a street that the person uses frequently. It also could be the loss of jobs in the same sector. Also, it might be something that happened in the past to people of the same ethnic group or the same religion or the same gender. Thus, we all constantly are being exposed to traumatic situations.

The first framework for traumatic incidents was developed in the 1970s because of the long-term psychological effects of the Vietnam War on soldiers in the USA. In the mid 1980s, the International Society for Traumatic Stress Studies was established as one of the first formal initiatives to recognize trauma as a distinct multidisciplinary field of study that explores how trauma affects not only individuals but also communities. Wars, natural disasters, climate change, forced migration, and their impact on individuals and communities has recently become an integral area of study. ${ }^{5}$

\subsection{Consequences of traumatization}

We have seen that the psychological consequences of such traumatization can be varied and can differ significantly between individuals, cultures, and situations. Commonly, they include depression, anger, anxiety, loss of direction, dissociation, and relational issues. There also is reactive psychosis. We must note that we call these "reactions" rather than "disorders", as we feel that people not reacting to such circumstances would be more ill than those having them. We also see that, while there are patterns to such reactions, the specific reactions are highly individual.

Somatic reactions are frequently present and are underestimated, in our view. These can affect every system in the body. Most frequently, we have seen circulatory system reactions, digestive system

\footnotetext{
${ }^{2}$ Draganić, P., Škribulja, M., Oštarčević, S. (2019). Potrošnja lijekova u Hrvatskoj 2013. - 2017. Agencija za lijekove i medicinske proizvode- Halmed pg. 145. Retrieved 3, 15, 2019, from :http://www.halmed.hr/fdsak3jnFsk1 Kfa/publikacije/Potrosnja-lijekova-uHrvatskoj-2013-2017.pdf\#page33

${ }^{3}$ Agger, I. (2001). Psychosocial assistance during ethnopolitical warfare in the former Yugoslavia. In D. Chriot \& M. Seligman (Eds.), Ethno-political warfare: Causes, consequences and a possible solution (pp. 305-318). Washington DC: American Psychological Association.

${ }^{4}$ Summerfield, D. (2000). War and Mental Health: a Brief Overview. British Medical Journal 321: 232-235.

${ }^{5}$ Psychologists for Social Responsibility, (2002). Personal and Community Reconstruction, Resilience and Empowerment in Times of Ethnopolitical Conflict. Washington, D.C.
} 
reactions, and immune system reactions, as well as endocrine system reactions, including sexual ones. In one study carried out by the Croatian Ministry of Defenders, it was found that the life span of war veterans was considerably decreased ${ }^{6}$. We thus feel that physicians also need to be involved in work with people reacting to trauma.

The societal consequences of trauma also seem to be mostly unrecognized. We have seen strong ecoomic consequences of trauma in the dysfunctionality at various levels mentioned above. Thus, there is a lack of concentration among workers, problems in planning, problems in execution of work, etc. Furthermore, psychological trauma leads to violence. This is true within families, that is, domestic violence, as well as within the community. We believe that unresolved psychological traumatization is a major unrecognized cause of violence and terrorism.

\subsection{Levels of traumatization and need for work}

Traumatic situations occur at a variety of levels. At an individual level, this can be intrapersonal, that is, a shift in the situation within the person, or it can be one or more reactions to an external situation. There also can be a traumatic situation at the family level. Further, traumatic situations can occur at the group level. A group here indicates people who have something in common. Additionally, trauma can occur at regional and national levels. An example of traumatic events at the global level would be climate change. Thus, it is seen that traumatic situations not only occur individually but also collectively and must be dealt with accordingly at the micro or macro levels. This has strong implications for peacebuilding.

Vamik Volkan commented that trauma in individual victims may cause new social and political processes at a broader social level and may result in altered behavior being transmitted from one generation to another. Neglecting the effects of trauma in one generation may lead to future generations carrying the suffering of previous ones, which Volkan terms transgenerational transmission. ${ }^{7}$ This type of transgenerational transmission can go on for hundreds, and some researchers say thousands of years. Recent studies have indicated that there may be a genetic component to it. It is extremely important in peacebuilding, as it may lead to future conflicts, psychological and physical suffering, and impaired functioning at the group and individual levels. Thus, it is important to work with the original trauma as early as possible.

\subsection{Capacity vs. elitism: Who works with the beneficiaries?}

We have stated earlier in this paper that there is a very great lack of capacity to deal with the psychological issues and reactions of people in violent and post-violent situations, as well as with vulnerable groups. This gap between need and availability of treatment is especially wide in low-income countries and middle-income countries ${ }^{8}$. In many places, this has been restricted to licensed psychologists and psychiatrists and, very occasionally, social workers. Yet, at least in some respects, this is not efficient, effective, or practical. We argue for the creation of a new group of people, that is, those without previous education in these fields, whom we call "barefoot therapists" or "peer supporters" who, in our experience, can be trained in about 120 hours and then supervised on an ongoing basis.

In terms of effectiveness, peers know the issues of one another far better than professionals. Also, peers can relate to one another more easily than people at a "higher" level. Furthermore, there are more peers than professionals available within the community. Thus, we would argue that, if peers can be adequately trained and supervised and know the limits to which they can work properly, they are a better resource than "professionals". Our experience is that they can become even more professional than the professionals in quite a number of instances. One problem in this is that they are not recognized officially and that the quality of their education and supervision is not controlled.

This issue of capacity will not be able to be solved by training more professionals. That is too costly in terms of time and resources. Peer support has a long tradition in informal services and may complement mental health care promoting recovery orientation and destigmatization. Non-specialist health professionals, lay workers, affected individuals, and caregivers with training and appropriate supervision by mental health specialists are able to detect, diagnose, treat, and support individuals with mental disorders and reduce caregiver burden. ${ }^{9}$ This also provides a sustainable pool of people within vulnerable communities on a long-term basis through community-based programs and task-shifting approaches.

\footnotetext{
${ }^{6}$ Ministarstvo branitelja, (2012). Praćenje pobola i smrtnosti hrvatskih branitelja iz Domovinskog rata I članova njihovih obitelji.

7 Volkan, V. (1997). Bloodlines: From Ethnic Pride to Ethnic Terrorism. New York: Farrar, Straus and Giroux.

${ }^{8}$ Kohn, R., et al. (2004). The treatment gap in mental health care. Bulletin of the World Health Organization, 82: 858-866.

${ }^{9}$ Kakuma, R., Minas, H., van Ginneken N., Dal Poz M.R., et all. (2011). Human resources for mental health care: current situati on and strategies for action. Lancet, Nov 5; 378(9803):1654-63.
} 


\section{Pragmatic Empowerment Training (PET)}

The PET program was first developed in response to the requests of volunteers working with asylum seekers and refugees in The Netherlands in the late 1980s and early 1990s. When staff at asylum seeker centers and non-governmental organizations there, as well as social workers, nurses, and some physicians heard about what we were doing, they also requested it. We also have used PET with war victims in various locations in Croatia, Bosnia, and Serbia since the mid-1990s.

PET is based on Carl Rogers' concepts of participatory education. Rogers' Person-Centered Approach implies that, in a positive and safe climate of empathy and trust, a person is able to build personal power, self-acceptance, self-awareness, and self-trust, and that the person can be trusted to move toward psychological health without this being imposed by another person from the outside. ${ }^{10}$ For the most part, the participants determine topics that they wish to learn. They use their own experience in the learning process. We establish a climate that is pervaded by three conditions, that is, congruence, empathy, and unconditional positive regard. Thus, there is more discussion and practice than lecturing. The role of the trainer is changed to that of facilitator. Because people are working with one another, the cultural barriers are considerably lower than there would be in conventional education. We believe in the tendency of the group as a whole, and every individual in it, to find a way into deepened understanding of person-centered theory and practice. In other words, we are committed to the consistency between the theory of the approach and our community learning process.

In general, small groups meet for about an hour and a half to two hours per week. We carry out groups onsite and online. The online groups have a number of advantages. First, they save travel costs and time. Time schedules thus become more flexible. Further, online work allows people from different places to come together and share knowledge and experience. We do not set limits to the number of sessions.

Additionally, the nature of the discussions allows for supervision as well as direct education. Thus, participants can gain insight into their practical cases and issues from the experience of others. The program is adapted to the needs and desires of the participants in each specific group. In general, it includes a general introduction to work with people, self-care, inter-personal and group communication, an introduction to psychology and counseling, this concentrating on the specific situations of the participants, non-violent conflict transformation, civil society, human rights, and integration of vulnerable groups into society. In general, no charge is made for the program. We issue certificates of participation and completion, these stating what the program has included and the number of hours of participation.

\section{Results}

It is very difficult to quantify the results of PET. Thus, we only can use anecdotal evidence to justify the technique. What people who have been through the program tell us is that it provides them with the tools to provide care that otherwise would not be provided to people who otherwise would not seek it in places in which such care otherwise would not be available. They also tell us that they prefer to work with their peers rather than with the so-called professionals. In this sense, it opens up a variety of additional opportunities for work with potential beneficiaries.

We have used PET in variety of situations with a large number of beneficiary groups. We have found that calling the groups "educational" rather than "therapy" groups frequently, but not always, overcomes stigmatization. Our clients will refuse therapy, and they complain about their existential problems. We frequently can hear, "if I have a job, or papers, or a house I wouldn't have a problem". Another issue here is taking the work out of the pathological sphere, that is, speaking about "natural" "post-traumatic stress reactions" rather than about post-traumatic stress "disorder" or "syndrome". This is critical in recruiting and working with beneficiaries, in our experience.

One situation in which PET has been useful is with volunteers and staff members working in difficult situations with vulnerable people such as asylum seekers and refugees. These situations are present in the West and in violent and post-violent situations. Unfortunately, most organizations that use volunteers and even those who employ humanitarian staff, that is, inter-governmental and large non-governmental organizations, do not provide psychological training or psychological supervision. Thus, there are high levels of burnout and damage to beneficiaries.

Another situation in which we have used PET is with groups of the victims of war, both civilians and (former) military, in villages. Further, we have worked with specific demographic groups, such as women, youth, former soldiers, etc. We see PET as being useful in situations where the provision of

${ }^{10}$ Rogers, R. C., Lyon, H. C., Tausch, R. (2013). On Becoming an Effective Teacher-Person-centered Teaching, Psychology, Philosophy, and Dialogues with Carl R. Rogers and Harold Lyon. London: Routledge. 
psychological assistance is difficult because of a lack of trained personnel and where resources are extremely limited. This applies to disaster situations, including wars and natural disasters. We also see PET being used with vulnerable groups, particularly those that are suspicious of "establishment" experts. Examples are minority groups, groups of migrants in the process of integration, etc.

\section{Conclusions}

Post conflict environments have long-term negative psychological impacts. Attention must be devoted to the work on psychological trauma and its accompanying physical and societal consequences. Practitioners working in post-conflict regions also are repeatedly exposed to severe trauma and therefore have become susceptible to its long-term consequences on health and emotional wellbeing. They need to be familiar with the basic concepts of trauma. Neglecting the effects of trauma in one generation may lead to future generations carrying the suffering of previous ones, as it may lead to future conflicts, psychological and physical suffering, and impaired functioning at the group and individual levels. We also strongly believe that the healing of the wounds of trauma is a pre-requisite for social integration, and is a condition for peace. Psychological trauma has not been considered to be a primary factor in integration into society during and after conflict and in work with vulnerable groups.

The gap between need and availability of treatment is especially wide in low-income countries and middle-income countries. In many places, this has been restricted to licensed psychologists and psychiatrists and, very occasionally, social workers. Yet, at least in some respects, this is not efficient, effective, or practical. In brief, currently, there is a insufficient number of professionals to deal with the situation, nor can a sufficient number be trained within the foreseeable future. In less developed societies, there are strong stigma against mental health. We thus see the best solution in well-trained and well-supervised "barefoot therapists", who also may be called "peer supporters".

PET is a valuable technique that we see as deserving more attention and recognition, particularly in front line low resource situations and particularly in situations in which mental health care is highly stigmatized. PET is based on Carl Rogers' concepts of Person-Centered Approach that implies that person can be trusted to move toward psychological health without the another being imposed from the outside. Its financial costs and the amount of initial training required are relatively low. It may be carried out online, allowing the efficiency to be even greater. We are in the process of translating the content into self-paced online format.

We welcome inquiries and collaboration.

\section{References}

Lancet Global Mental Health Group, (2007). Scaling up services for mental disorders-a call for action. Lancet 2007; 370, 1241-52.

Draganić, P., Škribulja, M., Oštarčević, S. (2019). Potrošnja lijekova u Hrvatskoj 2013. - 2017. Agencija za lijekove i medicinske proizvode- Halmed pg. 145. Retrieved 3, 15, 2019, from: http://www.halmed.hr/fdsak3jnFsk1Kfa/publikacije/Potrosnja-lijekova-u-Hrvatskoj-20132017.pdf\#page33

Agger, I. (2001). Psychosocial assistance during ethnopolitical warfare in the former Yugoslavia. In D. Chriot \& M. Seligman (Eds.), Ethno-political warfare: Causes, consequences and a possible solution (pp. 305-318). Washington DC: American Psychological Association.

Summerfield, D. (2000). War and Mental Health: a Brief Overview. British Medical Journal 321: 232-235.

Psychologists for Social Responsibility, (2002). Personal and Community Reconstruction, Resilience and Empowerment in Times of Ethnopolitical Conflict. Washington, D.C.

Ministarstvo branitelja, (2012). Praćenje pobola i smrtnosti hrvatskih branitelja iz Domovinskog rata I članova njihovih obitelji.

Volkan, V. (1997). Bloodlines: From Ethnic Pride to Ethnic Terrorism. New York: Farrar, Straus and Giroux.

Kohn, R., et al. (2004). The treatment gap in mental health care. Bulletin of the World Health Organization, 82: 858-866.

Kakuma, R., Minas, H., van Ginneken N., Dal Poz M.R., et all. (2011). Human resources for mental health care: current situation and strategies for action. Lancet, Nov 5; 378(9803):1654-63.

Rogers, R. C., Lyon, H. C., Tausch, R. (2013). On Becoming an Effective Teacher-Person-centered Teaching, Psychology, Philosophy, and Dialogues with Carl R. Rogers and Harold Lyon. London: Routledge. 